\title{
The Research and Development of Remote Interactive Engine Room Resource Management Simulator
}

\author{
Wenlong Yao, ${ }^{1, a}$, Dezhi Jiang ${ }^{2, b}$, Yuan Liu ${ }^{3, \mathrm{c}}$ and Jundong Zhang ${ }^{1, \mathrm{a}}$ \\ ${ }^{1}$ College of Marine Engineering ,Dalian Maritime University; Dalian, 116026; China \\ ${ }^{2}$ Department of Marine Engineering, Qingdao Ocean Shipping Mariners \\ College,Qingdao,266071,China \\ ${ }^{3}$ Department of Naval Architecture and Ocean Engineering,Qingdao Ocean Shipping Mariners \\ College,Qingdao,266071,China \\ ayaowenlong@dlmu.edu.cn, ${ }^{b}$ jiangdezhi@coscoqmc.com.cn, ${ }^{c}$ liuyuan@coscoqmc.com.cn
}

Keywords: STCW convention;engine room resource management simulator; remote interactive.

\begin{abstract}
In this paper, the design scheme, technical route and system structure of the remote interactive engine room resource management simulator are proposed based on the study of the engine room resource management project. This paper introduces virtual reality technique, visual C\# and IE real-time interaction technology to the engine room resource management simulator and the development thoughts of the remote interactive engine room resource management simulator are elaborated based on the 3d modeling optimization and real-time interaction technology. This study can better meet the training requirement of engine room resource management in the STCW Manila amendments which include the teamwork training, situational awareness training, decision-making ability training, execution of strain deployment training etc.
\end{abstract}

\section{Introduction}

Engine room resource management is the compulsory training content that is the new addition in the STCW Manila amendments[1,2].According to the new convention, the theory teaching and operation evaluation are included in the training content of engine room resource management, but now the main function of the engine room simulator is the device operation training, it does not meet the training requirement of engine room resource management in the STCW Manila amendments which include the teamwork training, situational awareness training, decision-making ability training, execution of strain deployment training and so on[3], it can not satisfy the operation and assessment needs of engine resource management. Thus it is very important to develop the engine room resource management simulator. This paper presents the development thoughts of the remote interactive engine room resource management simulator by using virtual reality technology. It can provide the online multiplayer or remote interactive training function. Through developing the engine room resource management simulator, the costing, safety and effect of this training can be solved effectively, and it can better meet the needs of the training program of Maritime Bureau by implementation of closed type demonstration, guide type wizard and open free operation mode of training.

\section{Overall Design}

Developing the remote interactive engine room resource management simulator is the purpose of this research by using virtual reality technology and combining with the engine room resource management training program of Maritime Bureau. Though training the daily management and emergency treatment of two kinds of different tasks, each engineer's responsibility in different tasks can be made clear, the related arranged working procedures can be executed strictly, it can ensure the safety of sailing ships and reduce the potential accidents[4]. From the overall functional distinction, this simulator can be divided into three modules: the duty engineer's personal and multiplayer 
cooperative training module, remote visualization interactive control module, instructor station and online training module. The function of each module is designed as follows:

\section{The duty engineer's personal and multi-engineer cooperative training module}

The key of engine room resource management is how to train the team cooperation, communication, leadership and group decision making, situational awareness of engineers[5]. Therefore the simulator should have the real environment of ship. The purpose of multi-engineer cooperative training is to train the coordination ability with other engineers and the implementation of the operation procedures. Therefore the training of the ship draft, transverse inclination change, automatic start and stop of the equipment when engine room is flooded, and the emergency treatment during the fire indication of the engine room, the emergency treatment of the ship lost power should be performed by the simulator. The simulator can realize that the engineer log to the simulator virtually and achive the emergency behavior according to the rules by independent control of virtual characters to complete each operation and the robot (NPC) instead of the position that no engineer participate[6].

According to the above task training situation, the module in the design should satisfy the following three kinds of training demand:

(1). The basic operation training

Which contains: starting of paralyzed ship, standing by of the engine room, full navigation, at sea speed sailing,preraring for finish with engine, operation of auxiliary boiler, operation of oil separator, operation of special conditions of navigation and dealling with emergency situation and so on;

(2. The Senior operation training

Which contains: parameter quering and modifing of main engine remote control system, control mode selection under special working conditions, troubleshooting of system;

(3). The Management skills training

Which contains:training of communication, coordination of the chief engineer with other engineers during in conventional working conditions and in emergency case;

\section{Remote visualization interactive control module}

This simulator is developed with the TCP/IP structure based on the B /S model which has the modeling environment of opening, online debugging, and the real-time operation characteristic. The $3 \mathrm{~d}$ scene of the engine room can be browsed through the IE browser. Owing to using a special scene working environment,V.R.of the engine room can be rapidly downloaded and showed and be dynamicaly interacting with scene in real-time,and also overcome the disadvantages of traditional downloading mode,which images are delivered to user one by one from web server, the multi-engineer online team work training based on webpage can be realized through this. Which contains: forming teams to complete the stand by of main engine, navigational watch of the on duty group, the contaction of engine room with the bridge, the training of PSC inspection and other emergency drills.

\section{Instructor station and online training module}

Instructor station and online training module is a utility program designated for the instructor monitoring and remote control over the students working with the simulator in the network[7]. The following options are available from the instructor station: setups,resources,faults simulation,scenario editor and so on. This module enables also the observation of the following student's station just like the systems alarm, shaft revolution,event log and so on. Instructor station is connected by phone with the trainee station. Specific functions as follows:

(1) Start / stop control function

(2) Operation mode setting function

(3) External conditions (environment) setting function

(4) Operation training management function

(5) Fault simulation

(6) Online training 


\section{Technology Route}

According to the ship equipment information and practical investigation, combined with the engine room resource management training programs, the simulator adopts $\mathrm{B} / \mathrm{S}$ frame to develop.The realistic 3D model of the equipment are established based on the virtual reality software, the function of virtual roaming and remote real-time interaction are developed by ActiveX technology and visual C\# technology. Overall study plan is as follows:

(1).The realistic 3D model of the equipment in the engine room are established based on the actual size of engine room equipment by utilzing the Converse3D modeling tool and its development kit;

(2).For function simulation part,we utilze ActiveX of Converse3D by embedding C\# language to develop the engine room resource management simulator combined with the practical of the training.

(3).For the multi-engineer cooperative training based on IE browser part, we utilze the converse3D three-dimensional network platform and virtual community functions and embedding visual C\# language to develop the remote visualization interactive control module.

(4).This paper makes some improvements aimed to the traditional B/S model:first programmed by the socket and run it in the client port to achieve real-time transition of the dynamic data, then realized the display of dynamic data in browses port by adopting ActiveX technique. Provide concrete resources for browses by using HTTP protocol to ascertain Web server through unified resources localizes. The mode of the improved project still through browses to visit embedded Web server, yet which combined the advantages of $\mathrm{B} / \mathrm{S}$ and $\mathrm{C} / \mathrm{S}$.

\section{System structure}

In order to make the engineers to simulate ship management status as far as possible, the simulator must have sufficient simulation environment, so that the trainees can get and show the goal of training the skills required. The simulator should contains the 3D model of equipments as follows: ship hull, engine room overview, main engine and its propulsion system, diesel engine, automatic electric power station system, emergency generator room, engine control room, bridge, emergency control console, steering system, boiler system, the ballast water system, fire alarm and fire extinguishing system (including carbon dioxide system), bilge system, fuel system (including fuel tank, settling tank and daily tank), lubricating oil system (including storage tank, settling tank), compressed air system, cooling system and so on. The system structure is showed as Figs.1.

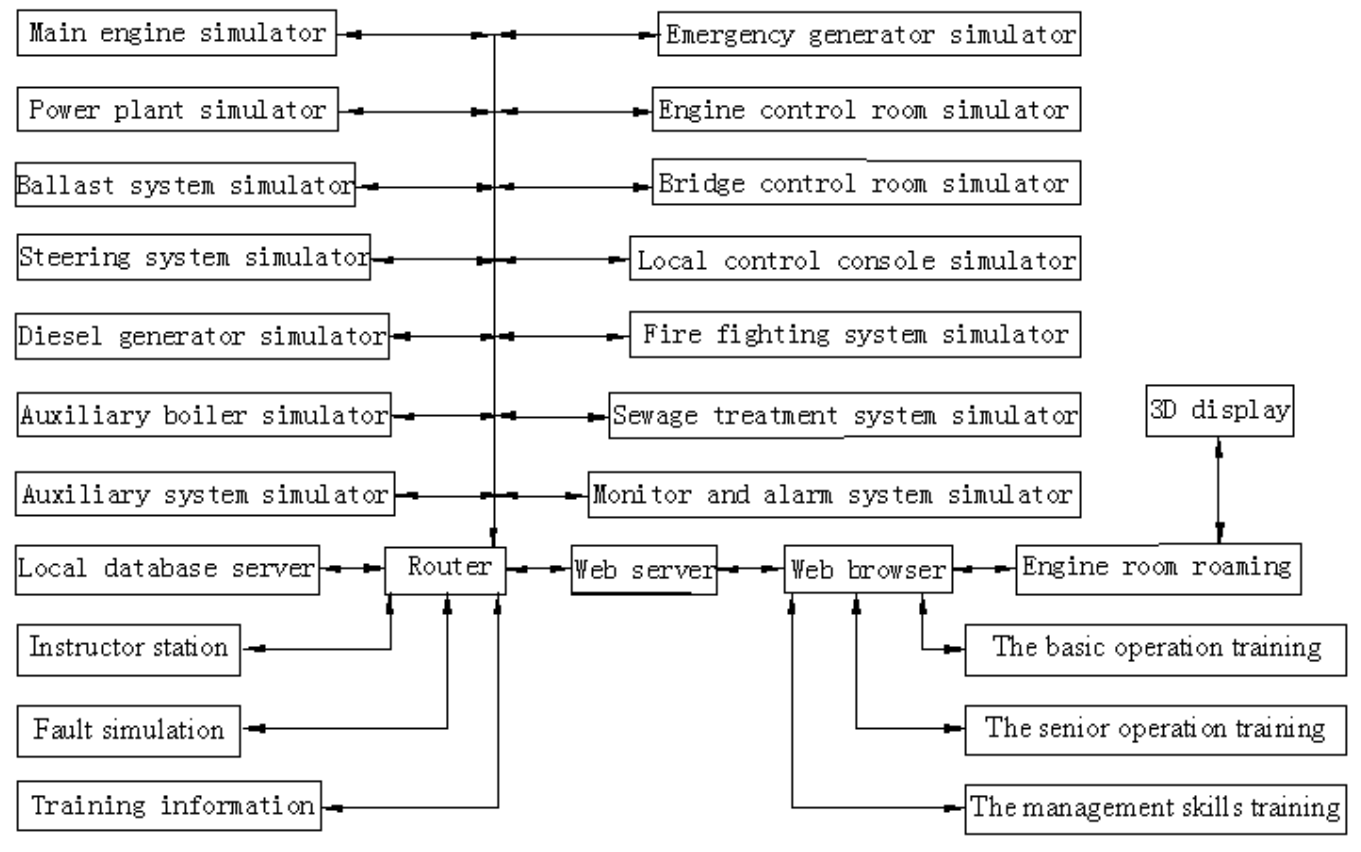

Fig. 1. Functional diagram of system structure. 
Through the remote Interactive engine room resource management simulator, we can not only to train the individual engineers during in normal and emergency conditions[8], but also to achieve the multi-engineer cooperative training and 3D model of browsing and interaction. The main training content includes as follows:

(1)At anchor:To train the operation skills of loading, unloading and stand by of the main engine;(2) Leave port: To train the operation skills of side thrust, maneuvering and quickly accelerated to sea speed;(3)At sea:To train how to operate the equipment during at sea;(4)Docking:To train how to complete the reduction, and use of maneuvering thruster for dock operation;(5)Start / stop of the auxiliary boiler;(6)Starting of Paralyzed Ship;(7)Communication of engineering department with feeding personnel during bunkering of fuel oil;(8)Black out and main engine malfunction;(9)Fault of steering system;(10)Fire in engine room;(11)Rough sea condition;(12)Ashore;(13)Collision/ stranding;(14) Pirate attack.

\section{Conclusions}

According to the STCW Manila convention amendment, engine room resource management was incorporated into the rules of STCW part A. This paper proposes a scheme that how to design the remote interactive engine room resource management simulator based on the resource management project, which can better satisfy the training and assessment requirements of maritime bureau for crew, it will provide great convenience for seamen especially in the remote training. After the completion,it will become the first engine room resource management simulator in the world.

\section{Acknowledgements}

The results discussed in this paper have been applied in the item of remote interactive engine room resource management simulator which was supported by COSCO (Projece No: 2012-1-H-004). This work was also supported by National Natural Science Foundation of China (51179102).

\section{References}

[1] Interpretation Group of STCW.The interpretation of STCW Manila convention amendment [J] . Maritime Education Research, (2011), p. 10-14.

[2] Christopher Young. The STCW Convention.(IMO Technical Support Program,1995).

[3] DeZhi JIang, Research of Engine Department Team Based on Engine Room Resource Management, ECWAC 2012,Wuhan,China,(2012), p. 35-40

[4] Hu feng. On the Factors Influencing the Work Efficiency of the Global Virtual Team and Possible Solutions [J]. Kunming: Journal of Yunnan Nationalities University,2005,22(6):pp 105-108. [5] Jiang Dezhi, Zhao Xiaoling. "Engine Room Resource Management" Using Engine Room Simulator [J]. Shanghai: Navigation of China,(2011), 34(1): p. 22-25

[6] LIANG En-sheng. human factor and the engine room resource management[J]. China Water Transport, (2009), p. 52-53

[7] A Mahapatra. Model Course [M] .( Train the Simulator Trainer and Assessor , 2012).

[8] Catherine Hetherington, Rhona Flina, Kathryn Mearns. Safety in shipping: The human element[J]. Journal of Safety Research, (2006) , p. 401-411. 